\title{
LA DANZA DE LA CONQUISTA
}

En mis investigaciones sobre el Romancero mexicano, topé con un tex to de La danza de la Conquista que me interesó, aunque poco tenía que ver con mis preocupaciones del momento. Se trata de un fragmento, publicado en prosa, pero obviamente versificado, que intenté reconstruir en su forma original. Ello me llevó a informarme sobre dicha danza y a examinar algunos textos a mi alcance. De ahí surgieron estas notas que ahora presento junto con el texto que les dio origen.

La danza de la Conquista es, en opinión del destacado antropólogo Arturo Warman', una derivación de la de Moros y cristianos, que tanto arraigo ha tenido en México.

Moros y cristianos nace en España al calor de la Reconquista, para insistir en el carácter guerrero y religioso de ésta y para conmemorar las victorias cristianas. Tiene varias realizaciones (danza, espectáculo de masas, representación teatral, etc.). Su difusión en la Península fue grande, y tenemos testimonios de ella desde el siglo XV. En el siglo XVI alcanza su máximo esplendor como espectáculo cortesano. A partir del siglo xvil quedó en manos del gobierno de las ciudades, es decir, de la alta burguesía y después, en manos de la pequeña. Hoy en día es parte de los festejos populares, generalmente de carácter religioso, en grandes zonas del territorio español ${ }^{2}$.

La danza ha perdido con mucho su aliento épico y ha adquirido con el tiempo personajes chuscos y populacheros ${ }^{3}$. Ha conservado sin embargo, y quizás se ha incrementado, su carácter religioso; en casi todas ellas se representa la lucha de los infieles capitaneados por Satán que son derrotados por los cristianos capitaneados por Santiago, un ángel o por la misma Virgen ${ }^{4}$.

Moros y cristianos aparece en México desde el momento mismo de la Conquista, cuando en España aún estaba en todo su esplendor. Según testimonio de Bernal Díaz del Castillo ${ }^{5}$ se llevó a cabo en Coatzacoalcos (en 1524/25) entre otros festejos organizados para recibir a Cortés, y son muchos los testimonios que tenemos de la celebración de este espectáculo público durante la época colonial. La fiesta arraigó en México y se sigue practicando, en sus varias manifestaciones, en casi toda la República; Warman (ibid., p. 141) agrupa todas ellas bajo la denominación de "Morisma", es decir danza o representación donde intervienen los moros; la "Morisma" comprendería pues Moros y cristianos, Santiagos, Danza de la Conquista, Danzas de concheros y espectáculos y derivaciones coreográficas diversas.

Del ciclo de la Conquista, al que pertenece nuestro fragmento, dice Warman que es una versión mexicana de la variedad teatral de Moros y

${ }^{1}$ Arturo Warman, La danza de moros y cristianos, México, 1972.

${ }^{2}$ Cf. Warman, op. cit., pp. 17-56.

${ }^{3}$ Cf. por ejemplo la descrita por RICARDoA RCO Y GARAY, Notas del folklore altoaragonés, C.S.I.C., Madrid, 1943.

${ }^{4}$ Para mayor información sobre estas fiestas cf. Primer Congreso Nacional de fiestas de Moros y cristianos (Villena, 1974), Alicante, 1976. Desgraciadamente no he tenido acceso a esta publicación, agotada en librerías y editorial.

${ }^{5}$ Apud Warman, op. cit., p. 74. 
cristianos; se trata de un enfrentamiento entre herejes y cristianos con el mismo corte y la misma estructura que ésta (ibid., p. 148).

El citado autor reporta en su libro algunos datos que pudieran explicar el nacimiento de esta variación particular y peculiar americana.

En 1572 se celebró en Alcalá de los Gazules, provincia de Cádiz, una representación en honor de los duques de Alcalá y del marqués de Tarifa en là que aparecían personajes de la conquista de México (Moctezuma, caciques, indios y españoles) y es de presumir, aunque no tengamos noticias de ello -dice Warman-que no fue ésta la única variante de tema americano de la tradicional fiesta de Moros y cristianos (ibid., pp. 40-41).

Por otra parte, en 1590 y ahora en México (Michoacán), se sustituyeron los moros habituales por indios chichimecas (los infieles) que lucharon contra los tarascos disfrazados de españoles (los cristianos) en una fiesta en honor de fray Alonso Ponce (ibid., pp. 98-99).

Todo ello nos indica que en la mente de los conquistadores el simbolismo de Moros y cristianos había tomado un nuevo rumbo. Acabada la Reconquista se abre el continente americano como escenario de nuevas luchas en las que no deja de intervenir el factor religioso. El infiel moro es remplazado por el infiel indio, al que hay que someter para convertir. No podemos saber hasta qué punto el celo religioso animó a los conquistadores (o a los guerreros de los tiempos de la Reconquista); la religión fue la justificación moral de la Corona española y de sus vasallos (como lo ha sido para tantos otros pueblos en sus guerras de expansión territorial o de dominio económico o político), y como fuerza moral, tenía que aparecer reiteradamente en cualquier manifestación social.

Los frailes, preocupados por la evangelización, favorecieron sin duda esta transposición de moros a indios, interpretación fincada en cierto modo en la realidad que estaban viviendo y que convenía a sus intereses, ya que la danza de la Conquista suele terminar con la conversión de Moctezuma y de toda su gente.

No tan difundida al parecer como Moros y cristianos, La danza de la Conquista se halla sin embargo en buena parte del territorio nacional: el litoral del Pacífico (en especial Oaxaca y Guerrero) y en Jalisco; a estos datos que nos proporciona Warman (ibid., p. 148), podemos añadir los estados de Puebla, Veracruz y Durango ${ }^{6}$. La danza ha llegado a Guatemala, Santo Domingo y Panamá, según los testimonios recogidos en esos países? No hay duda que una recolección a fondo mostraría la existencia de versiones en otros estados de la República y, quizás, en otros países americanos.

\section{LA RECOLECCIÓN DE TÉlLEZ GIRÓN:}

En los años 30, la Sección de Investigaciones Musicales del Instituto Nacional de Bellas Artes patrocinó el trabajo de campo de varios investiga-

\footnotetext{
${ }^{6}$ De acuerdo con las noticias que nos dan diversos investigadores, de los que hablaré más adelante.

${ }^{7}$ C.. Matilde Montoya, Estudio sobre el baile de la Conquista, USC, 1970; Penro Henrfquez Ureña, "El teatro de la América española en la época colonial" en Obra crítica, México, 1960; E.J. Castlllero, Los Montezumas, Panamá, 1948.
} 
dores. Informes y materiales no empezaron a publicarse hasta $1962^{8}$. De estas investigaciones nos interesan las de Roberto Téllez Girón en el estado de Puebla ${ }^{9}$, ya que contienen, diseminados en más de 100 páginas, varios datos sobre La danza de la Conquista, amén de un fragmento en prosa que trataré de reconstruir en su forma original. Muchos de estos datos son contradictorios o incompletos, pero no siempre pueden achacarse a descuidos por parte del investigador, sino a las dificultades que encontró para conseguir información.

Las localidades donde se baila La danza de la Conquista son Chignautla, Atempan, Yaonáhuac, Hueyapan y Zacapexpan, pero, según se desprende de lo dicho por los informantes, La danza... forma parte de los espectáculos que se presentan en los pueblos en ocasión de la fiesta del patrón, o de otra fecha significativa, y los ejecutantes de ésta y otras danzas, como Santiagos, Moros y cristianos, Toreadores, etc., viajan de pueblo en pueblo, atendiendo las diversas solicitudes. Es pues casi seguro que la danza se baila en toda la región de la sierra de Puebla cercana a Teziutlán y también en otras zonas del estado como Jonotla y Huauchinango ${ }^{10}$.

Parece haber dos modalidades de La danza de la Conquista: una sin "relación" que el informante Alberto Villa, natural de Zacapexpan y tocador de violín, denominó Danza de aztecas y españoles, y otra con "relación", la más difundida en la región, y que se llama Danza de los tocotines. Casi todos los informantes coincidieron en afirmar que esta "relación" está en "mexicano", sin embargo el fragmento que recogió T. G. está en castellano. Según unos músicos, la danza tiene 24 sones, según otros 15. Puesto que hay discrepancias, para la descripción de ambas modalidades nos fijaremos en los informes más completos, que son los de Alberto Villa para la primera y los de Anselmo Perdomo, natural de Atempan, para la segunda.

a) La danza de aztecas y españoles: Los participantes se dividen en 3 grupos: aztecas, tocotines y españoles; cada uno tiene un jefe llamado "caporal". Ocho sones acompañan la danza: 10: "entrada, español, puntapié", que bailan todos; $2^{0}$ "Marcha", que también bailan todos; 30 "Paso volado", que no bailan los tocotines; $4^{0}$ "Abanderado": los caporales español y azteca llevan respectivamente la bandera española y la mexicana y bailan solos medio són; después van en busca de su cuadrilla y bailan todos; $5^{0}$ "Guerra"; se simula una batalla con espadas; los españoles ganan y los aztecas huyen; $6^{0}$ "Diana de los españoles" [icelebración del triunfo?]; $7^{0}$ "Guerra", que ganan esta vez los aztecas; 8 " "Diana de los aztecas" en que bailan todos ${ }^{11}$. Como se ve, la danza tiene como tema la Conquista, pero

${ }^{8}$ Inuestigación folklórica en México. Materiales, México, 1962. Introducción y notas de Baltasar Samper.

${ }^{9}$ Roberto Téllez Girón. "Informe sobre la investigación folklórico-musical realizada en los distritos de Teziutlán, Tlatlauquitepec y Zacapoaxtla, estado de Puebla y Jalacingo, estado de Veracruz, en junio y julio de 1938" en Investigación folklórica en México, pp. 351-404, e "Informe sobre la investigación folklórico-musical realizada en los distritos de Teziutlán, Tlatlauquitepec, Zacapoaxtla y Municipio de Huitzitlán, estado de Puebla y distrito de Jalacingo, estado de Veracruz, en agosto y septiembre de 1938", ibid., pp. 405-486 Me referiré desde ahora al autor y su obra como T.G.

${ }^{10}$ Una de las danzas citadas por T.G. procede de un músico de Jonotla (T.G., p. 388) para la segunda ubicación cf. el artículo de V.T. MENDOzA citado infra, nota 19.

${ }^{11}$ T.G., op. cit., pp. 387-388. La música se halla transcrita en las pp. 400-402. 
termina con el triunfo de los aztecas. Quizás tenga su origen en algún enfrentamiento histórico entre ambos bandos, pero más bien parece un simple arreglo patriótico para que los indios sean finalmente los triunfa. dores. Con este enfoque, es natural que la "relación" original correspondiente al modelo común de la Danza de la Conquista no pueda tener cabida en esta estructura, pues los españoles, como portadores de la fe, no pueden aparecer vencidos, ya que la religión está por encima del honor nacional. Es pues muy comprensible que la danza no cuente con tal "relación" y se limite a música, danza y pantomima.

b) La danza de los tocotines ${ }^{12}$ es la que nos interesa más ya que a ella pertenece el fragmento de "relación" del que después se hablará. Tiene, como se dijo, 15 sones: 10 "Introducción y Són de gracejos"13, $2^{0}$ "Són", 30 "Són del monarca y su batalla", 40 "Són de Cortés y su batalla", $5^{0}$ "Combate de Cortés y el monarca", 60 "Baile de Alvarado y su capitán", 70 "Són de Cortés", $8^{0}$ "Són de Cortés y Maringa", $10^{0}$ "Són del monarca", 110 "Primer baile de Cortés y el monarca", $12^{0}$ "Segundo baile de Cortés y el monarca", 130 "Tercer baile de Cortés y el monarca", 140 "Combate general", $15^{0}$ "Despedida" (T.G., p. 422). Se canta solamente el $10^{\circ}$ són y es el músico (tocador de violín) quien canta la siguiente cuarteta: "Proseguid, monarca, / baila tocotín / con pasos mudanza / y cuerpo gentil"'14 (ib., p. 454). Por los títulos de los sones no podemos saber con certeza si la estructura de la representación es semejante a la común: triunfo de los españoles y conversión de los indios, o si, a semejanza de la danza antes citada, termina con el triunfo indígena, pero la existencia de una "relación" nos hace pensar que debe tener la estructura común.

\section{La "relación"}

a) Texto publicado: En las páginas 423 y 424 de la citada obra de T. G. aparece un fragmento de la Danza de los tocotines que fue escrito, de puño y letra, por Anselmo Perdomo, director del grupo de danzantes, y que reproducimos a continuación, tal y como apareció publicado. No sabemos a qué parte de la danza corresponde, pero, por su contenido, debe lógicamente tener lugar antes del combate entre ambos jefes, ya que describe la primera embajada que manda Cortés a Moctezuma:

"Cortés: (1692). Hagan alto mis soldados suspendan los escuadrones, hagan manciones en el puerto hunos y otros batallones, todos en conpuestas filas que sustiendan y qué se alogen, los grandes y sentinelas el orden no lo despogen, todos los más principales, mi mandato han de observar, para que cuándo sea el al to, empesemos a marchar entre tanto tengo dispuesto, que vaya con mi enbajado el sin segondo alvarado contra esta Gente mavada pidiéndoles $\mathrm{Paz}$ primero como obcerva nuestra Ley. En nombre y parte mía, a toda esta indiana ingrey: Ve alvarado y les propones que sí me dejan entrar les empeño

12 "Tocotines", según T.G. (p. 423), son los ejércitos de los personajes centrales, es decir de Cortés y Moctezuma.

${ }^{19}$ Los gracejos son, como su nombre lo indica, "una especie de payasos... que hacen chistes constantemente" (T.G., p. 423). 446-457.

${ }^{14}$ T.G., p. 454. Los textos musicales, así como la letra de la cuarteta están en las pp. 
mi palabra de qué los ede estimar, pero seácaso son rebeldes no admito, en este partido y en este Reino junto ninguno a de que dar vivo:

Alvarado: Tambreve voy a partir que de mi vuelta has de dudar, de la respuesta qué traiga, es lo que te hede contestar.

Imbencible Moxtesuma Monarca el mas opulento ímbicto Rey Señor de este Americano imperio, por parte del Gran Cortes nuestro hilustre Generál, te manda qué de su parte te declare la embajada: como á llegado de Paz, y para hacer su entrada necesita tu licencia bajo tu reál Palabra, qué le permitas la beña de que llegué a contestar ciertas cosas secretas qué a los dos, a de.importar; y sabras que trae consigo para su reál acistencia, tres cientos hombres guerreros para entrar con mas deciéncia, y entre tanta gente os digo como su prosafia es fina traé interpete qué aclare a quella Hermosa Marina; ella dira los intentos el motivo que tenemos de haber llegado a esta tierra para bolvernos sin Guerra; ahora espero tu respuesta, pues lla acave mi embajada, que detras de esta rivera tengo mi gente enojada:

Moxtesuma responde: Español hijo del Sol que me hás dejado abismado, de ver tu fina presencia y lo hermoso de tu agrado, hoy mismo llevaras la respuesta; que me has dejado encantado; responde tu sobrino a este allado Soldado:

Cacique responde por Moxtesuma a Alvarado:

En el nombre del Gran Señor, dueño de esta monarquia que es la América mas grande que a dado rayos al día yo respondo por él; qué le estima su atención, pues que venga en hora vuena el y todo su escuadron le empeño su reál palabra con todo lo consultado y él, mismo saldra al encuentro, a recirle su ofertado; pues dice que tiéne mucho gusto de verlo en su reino entrar; pues dice que viene de paz y qué no quiere peliár; yo de mi parte digo que no es miedo ni temor, en consentirles la entrada porque nos sobra valor; el menos estos que mirán, con esfuerzo sin segundo, soy copeteme y capaz, de oponerme a todo el mundo:

Esto le he respondido, dile que venga mañana, hantes qué extienda el Sol, en los Pabellones de grana:!

Maestro

Anselmo Perdomo (Firmado)".

b) Reconstrucción del texto poético: Es obvia la forma versificada de la relación. Las deformaciones, producto de la repetición, en parte mecánica, son múltiples y consisten primordialmente (aparte de la que supone la ortografía de la transcripción) en contaminaciones de tipo fonético, cambios posicionales de letras, palabras, versos o hemistiquios, cambios de género y número, adición o supresión de elementos menores como preposiciones y conjunciones, y aun de elementos como sustantivos, y deformaciones fonéticas. He tratado de reconstruir los versos ateniéndome al metro (doble octosílabo), rima (pareados, generalmente consonantados) y, desde luego, al sentido. Sin embargo, no siempre he acertado con la enmienda y algunos versos me parecen dudosos. He aquí el texto reconstruido:

Cortés:

-Hagan alto, mis soldados, suspendan los escuadrones, hagan mansión en el puerto unos y otros batallones; todos en compuestas filas que se extiendan y se alojen, los grandes y centinelas el orden no lo despojen.

5 Todos los más principales mi mandato han de observar para que cuando sea el sol alto empecemos a marchar. 
En tanto tengo dispuesto que vaya con mi embajada el mi segundo Alvarado contra esta gente malvada, pidiéndole paz primero como observa nuestra ley,

10 en nombre y de parte mía a toda esta indiana grey. Ve, Alvarado, y les propones que si me dejan entrar, les empeño mi palabra de que los he de estimar; mas si acaso son rebeldes, no admitiendo este partido, en todo este reino junto ninguno ha de quedar vivo.

Alvarado:

15 - Tan breve voy a partir que de mi vuelta has de dudar, de la respuesta que traiga es lo que te he de contestar. Invencible Moctezuma, monarca el más opulento, invicto rey y señor de este americano imperio, por parte del gran Cortés, nuestro ilustre general,

20 me manda que de su parte te declare la embajada: Como ha llegado de paz y para hacer su entrada necesita tu licencia bajo tu real palabra, que le permitas la venia de que llegue a concertar ciertas cosas muy secretas que a los dos han de importar.

25 Y sabrás que trae consigo, para su real asistencia, trescientos hombres guerreros para entrar con más decencia; y entre tanta gente, os digo, como su prosapia es lina, trae de intérprete que aclare a aquella hermosa Marina. Ella dirá los motivos de haber llegado a esta tierra

30 y el intento que tenemos para volvernos sin guerra. Ahora espero tu respuesta, pues ya acabé mi embajada, que detrás de esta ribera tengo mi gente alojada.

Moctezuma:

-Español, hijo del sol, de ver tu fina presencia que me has dejado abismado y lo hermoso de tu agrado,

35 hoy llevarás la respuesta, que me has dejado encantado. Responde tú, mi sobrino, a este gallardo soldado.

Cacique:

-En nombre del gran señor, dueño de esta monarquía, que es la América más grande que ha dado rayos al día, yo te respondo por él: que le estima su atención,

40 pues que venga en hora buena él y todo su escuadrón; le empeña su real pálabra con todo lo consultado y él mismo saldrá al encuentro a decirle su ofertado: de que tiene mucho gusto de verlo en su reino entrar, pues dice que viene en paz y no quiere pelear.

45 Yo de mi parte te digo que no es miedo ni temor el consentirles la entrada, porque nos sobra valor; con menos de éstos que miras, con esfuerzo y sin segundo, soy competente y capaz de oponerme a todo el mundo. Esto le he respondido. Dile que venga mañana

50 antes de que extienda el sol los pabellones de grana.

c) Observaciones y notas

1) Notas al texto 
Verso $2 a$ : Para la medida del verso, y porque es la forma usual ${ }^{15}$, he trocado mansiones por mansión.

" 3b: He reconstruido el verso: que sustiendan y que se alojen. Quizás otra reconstrucción podría haber sido: "y que en sus tiendas se alojen".

4a: No le encuentro mucho sentido, pero no he acertado con la reconstrucción, así es que lo dejé tal cual. Quizás podría ser "colocando centinelas, que el orden...", pero me parece demasiado brusco el cambio de grandes por colocando.

6a: El texto dice: para que cuando sea el alto, lo que no tiene sentido. En mi reconstrucción sobra una sílába, así es que es posible que el verso original sea: para que con el sol alto.

7a: El texto dice entre tanto. He enmendado para la medida del verso: en tanto.

7b: Dice embajado.

8a: Dice sin segondo.

8b: Dice mavada.

10a: He añadido de.

10b: Dice ingrey.

13a: Dice se acaso. Ha cambiado pero por mas para la medida del verso.

13b: Dice: no admito en este partido, lo que no parece tener sentido, así es que creo gue no admitiendo este partido (tomando partido en su sentido de trato o convenio) es lo correcto.

14a: He suprimido la $y$ inicial para el sentido y he añadido todo por la misma razón, y también para el metro.

15/16: Estos versos parecen parte de un parlamento más largo que se ha reelaborado torpemente.

18a: He intercalado y para la medida del verso y por ser rey y señor la fórmula usual.

19/20: Si tomamos en cuenta que todo el texto está en pareados, parece faltar un verso después del 19 que rimara con éste. Seguramente contendría alabanzas a Cortés, en consonancia con las hechas a Moctezuma.

20a: Dice te manda, pero me parece más lógico me manda.

22b: El original dice: bajo de tu real palabra; me pareció que sobraba de.

22/23: Falta seguramente un verso después del 22, ya que sin él no queda clara la secuencia del sentido de los versos 21,22 y 23 . Además de ello, los versos 21 y 22 riman en consonante (áda) como los pareados normales, mientras que el 23 no tiene pareja y rima en asonante (áa) con los anteriores. Es cosa insólita en la versificación de este texto el que haya un grupo de tres versos, dos pareados consonantados y uno asonantado.

23a: Dice veña.

$23 b$ : Dice contestar. Creo que lo adecuado es concertar.

24a: He intercalado muy para cumplir con el metro.

24b: Dice $h a$. 
26b: Dice deciencia.

27b: Dice prosafia.

28a: Dice interpete. He añadido de para el sentido.

28b: He añadido $a$.

29/30: Creo que aquí ha habido una alteración de todo el dístico: Ella dirá los intentos, el motivo que tenemos / de haber llegado a esta tierra para volvernos sin guerra, no rima ni tiene sentido. En mi reconstrucción he cambiado el orden de algunas palabras y versos, restaurando, a mi parecer, sentido y rima.

32b: He cambiado enojada por alojada, porque es más congruente con el sentido de las palabras de Alvarado, que no son amenazantes (llegar de oaz, volver sin guerra, venia, licencia). Es posible que la mención de los 300 guerreros haya dado lugar al cambio.

35a: El texto dice hoy mismo llevarás...: he suprimido mismo para el metro.

36a: He intercalado $m i$ para el metro.

36b: El texto dice allado; lo he cambiado por gallardo.

37a: Dice en el nombre...; he suprimido el para conservar el octosílabo.

39a: Para el metro, he añadido te.

4la: Dice empeño, pero el sujeto es Moctezuma (el señor del verso 37 ).

42b: Dice recirle.

43a: Dice: pues dice que tiene mucho gusto; la fórmula inicial se repite en el verso siguiente y creo que ha dado lugar a un contagio que ha reemplazado una forma semejante a la que yo he recreado.

44a: Dice: de paz; me parece mejor en paz.

45a: El verso original no cumple con las 8 sílabas; por esa razón he intercalado te, pero podría haber sido le o bien y inicial.

46a: El sentido dicta cambiar en por $e l$.

47a: Dice: el menos estos que miran con esfuerzo y sin segundo, verso que no tiene sentido. Lo he reelaborado lo más cercanamente posible al original, pero estoy consciente de la debilidad de mi interpretación.

48a: Dice copetente.

50a: He intercalado de para metro y sentido.

50b: He suprimido el en inicial para metro y sentido.

\section{2) Observaciones generales al texto}

Figura, al principio del fragmento, una fecha entre paréntesis: 1692. Nada nos dice T. G. sobre ella, así es que suponemos que es la fecha que el maestro Perdomo asigna a la relación. La presencia de dicha fecha y la resistencia de Perdomo a dictar el texto (T.G., p. 423) parecen indicar la existencia de algún manuscrito, que Perdomo consultó para refrescar su memoria. Es muy común que los cantantes y recitadores populares apoyen 
la memorización de un texto oral en uno escrito ${ }^{16}$. A veces son copias del original y otras veces, plasmaciones por escrito del saber de otro cantor. Si el texto que nos ocupa procede de un manuscrito antiguo, copia más o menos exacta del original, no se explican las deformaciones, errores y olvidos que hay en el fragmento y que son, a no dudar, producto del paso por la tradición oral; por otra parte, una fecha tan poco significativa históricamente no es probable que sea invención de Perdomo ni que se haya transmitido oralmente durante más de dos siglos, puesto que no tiene ninguna relevancia para la historia que se relata, así es que sólo podemos suponer que la copia en poder de Perdomo es copia a su vez de una transcripción que hizo un cantor de un texto, aprendido oralmente, pero basado en el manuscrito original. Sólo así se puede explicar la presencia de la fecha, junto a la ortografía deficiente y los errores del texto de Perdomo. $O$ sea que, en el caso de nuestro fragmento la cadena de transmisión partiría de la lectura memorizada de un texto escrito (que contendría la fecha), continuaría con la repetición, más o menos fiel de lo aprendido, de unos cuantos transmisores (conservación de la fecha, pero deformaciones pequeñas del texto) y seguiría con la iranscripción de lo memorizado, de uno de esos transmisores (lo que explica la ortografía), plasmación escrita que pasó a poder de Perdomo, o de la cual él mismo sacó una copia ${ }^{17}$. Todo ello nos da una buena idea de las formas de transmisión que puede adotar un texto, y nos indica que, contra lo que generalmente se cree, los textos populares, en especial los largos, tienen realizaciones escritas durante su recorrido temporal ${ }^{18}$.

Tenemos pues un texto de finales del siglo XvII, con los cambios hechos por los sucesivos recitadores y, a no dudarlo, de los provocados por los errores del (o los) copistas. Los dos "estilos" se hallan presentes. Predomina desde luego el estilo semi-culto del creador o refundidor. Ejemplos típicos de este estilo original son "indiana grey", "invicto rey y señor", "prosapia", así como la sintaxis algo retorcida, que delatan la verbosidad del poeta menor que piensa con ello dar un estilo noble y literario a sus creaciones. Es insostenible, desde luego, la tesis de Mendoza que pretende que estos textos son de creación popular ${ }^{19}$. Es obvio que fueron compuestos por personas que poseían rudimentos de un arte poético que poco tienen que ver, en lo que se refiere al estilo, con el arte popular.

Es interesante observar en el texto las marcas de su tradícionalización. Las dos fuerzas que rigen la poesía popular están presentes: la conservación y la variación. La segunda es quizás la que ha dado resultados menos afortunados, ya que consisten primordialmente en deformaciones que oscurecen el sentido; sin embargo, hay recreaciones como los versos 15 y 16 , que saben conservar la rima en pareados, y variantes acertadas como enojada por alojada; también hay expresiones del habla común que popularizan el texto (como pero en vez de mas), aunque muchas veces afectan el metro. La conservación, en cambio, es notable, tanto en expresiones arcaicas como hacer mansión, como en palabras muy lejanas del habla de los

${ }^{16}$ Como es el caso de la mayoría de los textos que comentaré infra (pp. 18ss.).

17 "Perdomo... sabe leer y escribir y habla perfectamente el castellano" (T.G., p. 375).

${ }_{18}$ Varios destacados folkloristas han hecho notar la existencia de textos escritos, sobre todo en relación con este tipo de danzas; cf, por ejemplo, Warman, op. cit., pp. 143 y 159

19 Vicente T. MendozA, "Versos de la gran conquista", ASFM, 1 (1942), 123-125. 
recitadores, como abismado. Es de notar que si bien el metro sufre con las variaciones que se han hecho, se respeta casi totalmente la rima ${ }^{20}$ y los hemistiquios con menor errores son los segundos ${ }^{21}$, lo que denota la importancia que la rima tiene para la memoria del recitador.

\section{3) Nexos con la Historia}

Con todas las inexactitudes, idealizaciones e invenciones que son propias de cualquier narración literaria basada en un hecho histórico, $L a$ danza de la Conquista está mucho más fincada en la realidad que las restantes manifestaciones de la "Morisma". Si bien es cierto que muchas veces Moros y cristianos tiene referencias históricas, las más de las veces los textos se han estereotipado y se habla de "la conquista de Argel", "la toma de la Alhambra", "la conquista de Rodas", o simplemente "la toma de un castillo" 22. No pasa lo mismo con La danza de la Conquista que posee siempre rasgos históricos que, además, varían según el país: en el ya citado libro de Matilde Montoya (ver nota 7) se nos presentan cuatro textos recogidos en territorio guatemalteco. En ellos aparecen datos que tienen que ver con acontecimientos y personajes relacionados particularmente con la conquista de Guatemala. Así aparecen Pedro de Alvarado y Portocarrero, protagonistas por parte de los españoles tanto en la realidad como en la ficción. Por oarte de los indios aparece el rey Tecum (oersonaje real) y su muerte a manos de Alvarado (también real), así como varios caciques indígenas, ilustres actores en la gesta histórica, y, como se trata, no hay que olvidarlo, de textos literarios, se personifica en el personaje de Quiché a la monarquía de dicho nombre que regía en el país. Las muestras de geografía local son numerosas y entre ellas destacan, por su significado histórico, los ropónimos donde se libraron las más fuertes batallas durante la Conquista: Quetzaltenango, Palajunoj, Olintepeque ${ }^{23}$.

En las versiones mexicanas, los personajes son los de la propia realidad del país y los acontecimientos que se relatan están cercanos a los sucesos. Basándose tan sólo en nuestro fragmento, veamos sus conexiones con la realidăd histórica.

La embajada española es de por sí un dato falso, ya que todos los mensajes que mandó Cortés a Moctezuma fueron por medio de los enviados del emperador. El dramatismo del texto pide que sean los mismos españoles quienes se entrevisten con el monarca para presentar las peticiones de Cortés. Pero aun siendo este pasaje, como hemos dicho, históricamente inexacto, tiene antecedentes en la realidad: veamos a Bernal Díaz del Castillo ${ }^{24}$ :

En aquella sazón acordó Cortés que fuesen dos de nuestros capitanes, personas señaladas, a ver y hablar al gran Montezuma e ver la gran ciudad de Méjico y sus grandes fuerzas y fortalezas. E iban ya de camino Pedro de

${ }^{20}$ Sólo hay tres versos sin rima, uno de los cuales $(7 b)$ debe ser un lapsus o una errata ya que la palabra embajada está correcta en el verso 20

${ }^{21} 15$ deformaciones contra 24 en los primeros hemistiquios.

22 Cf. Warman, op. cit., pp. 30 y 88.

${ }^{23}$ Montoya, op. cit., pp. 113-134 y 190 ss.

${ }^{24}$ Bernal Diaz del Castillo. Historia verdadera de la conquista de la Nueva España, Madrid, 1928. 2 ts. 
Alvarado y Bernaldino Vázquez de Tapia... (p. 260)... y les escribió que se volviesen luego... Y desque vieron las cartas se volvieron (pp. 261-262).

Aunque yo personalmente creo que la embajada española es un requerimiento del texto, no deja de sorprender la coincidencia entre propósitos históricos y realización literaria.

En lo que se refiere al tema de la embajada, coincide en sustancia con lo que pasó. Es claro que se simplifican los acontecimientos (por ejemplo, no se mencionan las vacilaciones de Moctezuma ni las asechanzas que mandó que le hicieran a Cortés, antes de consentir en recibirlo (op. cit., pp. 267-293). Se condensan en un solo parlamento palabras dichas en las muchas embajadas que se cruzaron entre Cortés y el emperador. En esta condensación entran también datos y detalles que en la realidad están diseminados en el relato de los meses que duró la marcha de Cortés desde Veracruz hasta México. Veámoslos:

Que le permitas la venia de que llegue a concertar

ciertas cosas muy secretas que a los dos ha de importar

“...hemos pasado muchos meses e remotas tierras para la ver [a Moctezuma] e decille cosas que le serán muy provechosas" (p. 284).

Y sabrás que trae consigo para su real asistencia,

trescientos hombres guerreros...

“...y nosotros aun no llegábamos a cuatrocientos soldados" (p. 300).

trae de intérprete que aclare a aquella hemosa Marina

"He querido declarar esto porque sin doña Marina no podíamos entender la lengua de la Nueva España y Méjico" (p. 116).

Español hijo del sol, que me has dejado abismado

de ver tu fina presencia y lo hermoso de tu agrado

"Y los embajadores con quien iban dieron relación de ello a su Montezuma... y parece ser que dijeron quel Pedro de Alvarado era de muy linda gracia, ansí en el rostro como en su persona, y que pareseía como al sol... y desde entonces le pusieron de nombre Tonatio, que quiere decir el Sol o el Hijo del Sol..." (p. 262).

Responde tú, mi sobrino, a este gallardo soldado

"Luego acordó enviar a un su sobrino, que se decía Cacamatzin, señor de Tezcuco, con muy gran fausto, a dar el bienvenido a Cortés y a todos nosotros" (p. 295). 
y él mismo saldrá a su encuentro a decirle su ofertado

“... el gran Montezuma que venía cerca, en ricas andas, acompañado de otros grandes señores y caciques que tenían vasallos. Ya que llegábamos cerca de Méjico adonde estaban otras torrecillas, se apeó el gran Montezuma de las andas ..." (p. 300).

Alusiones todas éstas a la realidad, y que fincan el texto en el pasado histórico. El autor o recreador maneja ciertos datos, unas veces conservando su sentido original y otras cambiándolo para que quede acorde con el sentido total del texto; por ejemplo, el número de soldados de Cortés es visto por Bernal Díaz como escaso y en nuestro fragmento como amenazador.

La danza no rememora sucesos ajenos, como sucede con Moros y cristianos, sino acontecimientos propios del país donde se ejecuta. Los autores de los textos dieron, seguramente desde el principio, rasgos muy positivos a la parte perdedora y los refundidores o los creadores más modernos siguieron esta pauta con mucha más razón, puesto que no eran españoles. Sin embargo, su religión no les permitió maltratar demasiadoa los portadores de la fe, ni su cultura deformar la historia, así es que dentro de estos márgenes impuestos, hicieron lo que pudieron por dignificar a los derrotados y disminuir a los vencedores. Nuestro texto es muy corto para que esto se evidencie claramente, pero hay indicios de ello por ejemplo en el parlamento del cacique, donde no sólo se alaba grandielocuentemente a Moctezuma, sino que se recalca su generosidad y nobleza y, sin que venga mucho al caso, se patentiza la valentía-del cacique (extensible a todos: "porque nos sabra valor") y su poderío como guerrero ("soy competente y capaz de oponerme a todo el mundo"). Esta última parte, que huele a valentonada, no lo es, ya que representa un inten to por parte del autor de borrar la acusación de cobardía que pesa sobre Moctezuma y algunos de sus seguidores. Al conjugar, como lo hace el texto, la nobleza y ooderío del emperador y la de los suyos, se da a entender que en la derrota intervinieron factores ajenos que no merman en nada el coraje y la dignidad india.

En el fragmento no se hace mención de la faceta religiosa de los conquistadores, sino tan sólo de la guerrera, en sus dos vertientes: fuerza y maña, manifiestas tanto en el parlamento de Cortés como en el de Alvarado. Es patente la ausencia de la mano del fraile catequizador, que no hubiera desperdiciado la oportunidad de mencionar desde el inicio los propósitos evangelizadores de los españoles. Es obvio también, al menos por el contenido del fragmento, que su autor es mexicano y tiene gran simpatía por los indios, a los que siente más suyos que en este enfrentamiento entre sus dos ancestros. Ello no quiere de ninguna manera decir, como opina Vicente T. Mendoza (op. cit., p. 123) que la danza nos da "la manera de concebir e interpretar la historia de los indígenas". Aunque no hay que descartar la intervención popular en la que se mezclarían quizás recuerdos de los acontecimientos transmitidos por tradición oral, me parece que los textos de la danza, compuestos originalmente por frailes sobre el modelo de Moros y cristianos, fueron recreados total o parcialmente por personas cultas de la región o por poetas de oficio. Este fragmento me parece un buen ejemplo de este tipo de recreaciones que no se 
alejan más que mínimamente de la realidad histórica básica, cuyo lenguaje, versificación y estructura indican la mano educada, y el tratamiento del tema la visión, no del indígena, sino del mestizo. Todo ello indica un autor con acceso a formas de cultura más amplias de las que, desgraciadamente, están al alcance de los medios populares.

\section{INFORMACIÓN SOBRE TEXTOS}

Aunque, al decir de varios folkloristas, La danza de la Conquista se baila en muchos puntos del país, tenemos escasas descripciones de ella y sólo un reducido número de textos de su "relación", todo ello diseminado en diversas publicaciones que cubren más de medio siglo. Me parece interesante resumir aquí algunas de estas publicaciones a las que he tenido acceso, pues abarcan un período de tiempo y un territorio lo suficientemente amplios para ser representativas y para que una comparación entre ellas (incluyendo las ya examinadas supra) permita dar una idea de las constantes y de la amplitud que existe en su presentación y realización. Las publicaciones a las que voy a referirme son cinco: 1) "Versos de la gran conquista", manuscrito en náhuatl comentado por Vicente T. Mendoza ( $o p$. cit.,) procedente de Xico, Puebla, al que denominaré: versión de Xico; 2) "La danza de la Conquista", texto procedente de Juchitán, Jalisco, publicado por José Cornejo ${ }^{25}$, al que me referiré como: Jalisco I; 3) "Cuaderno de la danza de la Conquista", publicado por Francisco Talavera ${ }^{26}$, versión recogida en Mezcala, Jalisco, y que denominaré: Jalisco II; 4) La danza de la Malinche, procedente de Sayula de Alemán, Veracruz, que nombraré: versión de Sayula ${ }^{27}$; 5) "La danza de los Montezumas", texto procedente de Panamá, pero de origen incuestionablemente mexicano, al que me referiré como: versión panameña ${ }^{28}$. Para las versiones ya descritas publicadas por Téllez Girón utilizaré las abreviaturas de: Aztecas y españoles y versión de Atempan para el fragmento objeto primordial de este artículo.

Versión de Xico: El manuscrito que comenta Mendoza está copiado en 1879 por el Sr. Atenógenes Téllez de otro más antiguo fechado en 1840. Mariano Jacobo Rojas hizo la traducción al castellano, misma que sirve de base al comentario. Según lo dicho por el Sr. Mendoza, el meollo temático es la conversión de los indígenas a la fe cristiana; el manuscrito comienza trunco con una exhortación, seguramente de Cortés, a Moctezuma, seguida de alabanzas al poderío de Carlos $\mathrm{V}$ por un lado y de Moctezuma por otro, amén de un despliegue, por parte de Cortés, de símbolos y lecciones

25 Jose Cornejo Franco. "La danza de la Conquista", ASFM, 4 (1944), 155-186.

${ }^{26}$ Francisco Talavera S., "Cuaderno de la danza de la Conquista", Anales dellNAH, época $7^{\circ}, 6$ (1976), pp. 149-178.

${ }^{27}$ La danza de la Malinche, México [1978]. "Antecedentes" por Marina Anguiano y Guido Münch, "Música, baile, canto e indumentaria" por Miguel García.

${ }^{28}$ No he podido consultar directamente el texto publicado por Castillero (op. cit.). así es que he utilizado la reedición que hizo Julio Arosamena: "Danza de la Montezuma española en Villa de los Santos", Revista Nacional de Cultura, Panamá, 1 (1975), 34-51, publicación que me fue proporcionada por el destacado folklorista mexicano Jas Reuter. El texto de Castillero también fue reproducido por Eduardo Matos Moctezuma, "La danza de los Montezumas", Anales del INAH, 18 (1965), pp. 71-92. 
cristianas. Cuauhtémoc se opone a los españoles y por ello provoca una batalla que termina con el triunfo español y la conversión indígena. Los personajes son, además de los nombrados, cuatro caciques indígenas y los capitanes de Cortés. En los intermedios del diálogo aparecen indicaciones para la ejecución de trozos musicales: "Cadena", "Pan de mesa" (de clara simbología cristiana), "Són para que baile el monarca", "Arribita muchachos" y "Valona", en que los participantes bailan. Es pues un texto mixto, con diálogo, danza y pantomima, y su estructura temática es muy semejante a las descritas por Warman en el libro antes citado.

Versión Jalisco I: El texto, en castellano como los que describiré más adelante, parece más amplio que el anterior, ya que además de Moctezuma y Cortés, aparecen también 4 capitanes españoles, cinco reyes indios, doña Marina ${ }^{29}$, un personaje de nombre Chimal, portavoz del monarca, un negro, dos viejos y dos soldados. Todos tienen su parte en el diálogo. En esencia, el argumento es el mismo: intento de cristianización, autoalabanzas, rechazo de los indios, guerra, triunfo español y conversión de los vencidos. La estructura se amplía con desdoblamientos y escenas secundarias; así hay varias embajadas, tanto de parte de los españoles como de la de los indios; el desacuerdo entre ambas partes se desdobla en peleas verbales personales (rey de Tlaxcala y Alvarado, rey de Tezcoco y Solis, etc.). Hay además un intento de soborno a Cortés, con las naturales entrevistas, y una escena de amor y cristianización entre Cortés y doña Marina. Durante la guerra, cada personaje indio se enfrenta verbalmente a un español y se rinde a él, con la consiguiente conversión. Al final todos dicen loores a María y hay un duo cantado por Cortés y Moctezuma con el mismo sentido. La "despedida" está a cargo del rey de Tlaxcala y es una contaminación de Moros y Cristianos, según explica en nota el Sr. Cornejo. El texto contiene algunos anacronismos, que también observa el recolector, como referencias a las luchas de Independencia (bastante explicable dado que los antagonistas son los mismos en la mente del hombre común) y también a otros episodios de la historia de México: la Federación, la República e, incluso, se menciona a los tejanos. Hay en el texto unas cuantas frases en náhuatl con su correspondiente traducción. En varias partes hay indicaciones de intervención de la música: "toca el violín", "Marcha", "toca el tambor", pero nada se nos dice sobre los sones interpretados.

Versión Jalisco II: Felipe Sanabria, "empresario" de la danza ${ }^{30}$, puso por escrito, hacia 1923, el texto que guardaba en la memoria. La versión tiene varios puntos de contacto con Jalisco I: repeticiones textuales de varios parlamentos, canciones en boca de doña Marina, el título que le da a Cortés (de Monroy), el personaje indio de Chimal, y algunas semejanzas más; tiene también unas frases en náhuatl (aunque no las mismas que Jalisco I) y varios anacronismos, notablemente de la época de la Independencia. Sin embargo, Jalisco II, aunque aprovechó sin duda partes de una versión semejante a Jalisco I, es diferente ya que contiene muchísimas más alusiones históricas en personajes (García de Olguín, capitán de berganti-

${ }^{29}$ Doña Marina es conocida también como La Malinche o Malinchi.

${ }^{30}$ Cada grupo de danzantes tiene un director, que es el depositario del texto oral oescrito y quien distribuye los papeles a cada actor, enseña la coreografía, proporciona los textos de los diálogos, etc. 
nes, Cristóbal de Olid, capitán de Cortés) y acontecimientos (derrota de la Noche triste, ahorcamiento de Xicoténcatl, construcción de buques para el ataque a Tenochtitlan, mención del tesoro imperial oculto en el lago de Texcoco, y otras más); también tiene varias menciones geográficas (Papantla, Ajijic, Los Reyes, Victoria y Texcoco). Su lenguaje es más altisonante y tiene otras peculiaridades como la confusión, a veces, de Moctezuma con Cuauhtémoc, la mención de Huitzilopotztli, que simboliza los dioses indios, y numerosos vivas y mueras ya a España, ya a México ${ }^{31}$. La Malinche (cf. nota 29) tiene también un papel más largo: además de la escena de amor con Cortés tiene dos escenas con Moctezuma; en la última, el emperador la acusa de traición. El ambiente de lucha guerrera es muy superior al de evangelización. Se ve claro que lo que le interesa al recreador es enfrentar a ambos bandos y poner de relieve la valentía de los indígenas frente al invasor.

Como en la versión Jalisco I, hay numerosas embajadas, amenazas por ambos lados, escaramuzas, guerra y conversión final. Termina la relación con el anuncio de la próxima muerte de Moctezuma (que aquí es confundido con Cuauhtémoc) y con vivas a España y Cortés y mueras a Moctezuma, Huitzilopotztli y México. Para borrar esta mala impresión, el último parlamento es el del gracejo: "Mentira que me rinda / a las armas de Cortés / Vuélvase la guerra danza..." que deja intacto el honor de los indígenas. Los principales personajes coinciden con Jalisco I, pero se han añadido 2 escuderos y un capitán español y dos reyes indios y un guerrero. En el texto hay indicaciones de baile para los personajes indios, ya en grupo, ya individualmente; hay dos menciones de canto, a mbas corresponden a doña Marina, y algunos de los versos que se utilizan pertenecen a canciones líricas existentes. Los instrumentos son tambor y violín. No hay indicación de los sones ni transcripción musical.

Versión de Sayula: Esta danza se baila en, Sayula de Alemán, pueblo cercano a Tenayuca, y en otros pueblos del estado de Veracruz; se acompaña con jarana, instrumento típico, y comprende 12 sones, de los cuales sólo se nos dan los nombres de: "Cortesías" (cinco sones), "Corrida del monarca", "Guerra" y el último, que da su nombre a la danza: "Las Malinches". Los personajes son los habituales: Moctezuma y sus capitanes o reyes, Cortés, Alvarado, doña Marina (a quien se nombra Malinche) y, caso no común, la esposa de Moctezuma. El argumento se enriquece con sueños y alucinaciones proféticas del emperador y su esposa que anuncian la llegada de los españoles; hay manifestaciones de apoyo y valentía por parte de los reyes indígenas (son las "Cortesías") y de los soldados españoles, y dos embajadas, una para cada bando (intento de cristianización e intento de soborno con oro, ambos rechazados), además de una entrevista entre los dos jefes y la guerra, que ganan los cristianos. La Malinche, contra lo que pudiera creerse, no tiene un papel principal: se limita a prevenir a Alvarado, a asegurarle la ayuda del rey de Tlaxcala y a declararse afecta "a la española nación". El canto de "Las Malinches", que finaliza la danza, tiene poco que ver con este personaje: resume el drama: profecías, guerra y

31 Además de estas exclamaciones que forman parte del texto de la "relación", los danzantes de esta versión llevan escrito en las capas: "Viva España", "Viva México" según el bando a que pertenezcan (Talavera, op. cit., p. 154). 
prisión del emperador y acaba con unas coplas en loor a San Isidro (en cuya fiesta se ejecuta la danza) y una cuarteta que concluye la representación: "Y con este adiós; aquí finaliza / del rey Moctezuma / toda su conquista". El texto es mucho menos extenso que los de Jalisco y más sencillo en su estructura. Los editores no intentaron reconstruir los deformados versos de una gran parte de la obra; sólo las "Cortesías" y "Las Malinches" están presentadas en verso, quizás porque son las menos maltratadas, aunque hay trozos de los diálogos que se podrían rescatar.

Versión panameña: En Panamá existe un curioso texto: Danza de la Montezuma, que relata la conquista de México. Julio Arosamena, autor de uno de los artículos donde se publica (cf. nota 28) dice que debió ser llevado a tan lejanas tierras por algún fraile; si éste es el caso, es evidente que ha habido una reelaboración, ya que en el texto se da poquísima importancia a la evangelización y mucha a la conquista del imperio azteca. No es ésta la única diferencia con los textos ya citados: es mucho más favorable a los españoles (sin dejar de dignificar a los indios), su lenguaje es, generalmente, de tipo popular, aunque no faltan los pasajes rimbombantes, los nombres de los capitanes españoles (marqués de Veracruz, conde de Lira) y de los caciques (Tortolí, Cristolito y Uralla) muestran la distancia que se ha establecido entre el tema de la obra y el territorio donde ha arraigado esta versión; el final es también original, ya que Cortés quiere enviar a Moctezuma a España, pero ante los lamentos de éste, lo deja en libertad. La estructura es bastante sencilla: una introducción de tema religioso (coro de indios y españoles), aviso de la llegada de los conquistadores, embaijada amenazadora de Moctezuma, encuentro de los dos jefes en el que Cortés pide, no la conversión, sino el sometimiento a Carlos V; caciques y españoles pregonan su valentía y poderío y tiene lugar una escaramuza con enfrentamiento de los jefes, cuyas hazañas y valor pregona un coro de indios o de españoles, nueva embajada india en que el embajador cae preso y se lamenta cantando (y Moctezuma le responde en la misma forma); después hay una embajada de Cortés oara volver a pedir la rendición de Moctezuma, quien intenta el soborno, que es rechazado. Cortés toma preso al emperador y la obra termina con su liberación, como se dijo antes. Las menciones religiosas son muy escasas, aunque desde luego sí existen, pero la diferencia fundamental entre este texto y los otros que se han visto es que la "danza" no se baila, se representa, y se mezclan canto y diálogo32; sólo hay un baile (del segundo embajador indio) de un típico "oaso" panameño, y algunas marchas. Estamos pues en presencia de una variante más cercana a ciertas expresiones españolas de Moros y cristianos que a las indígenas de la "Morisma" de que nos habla Warman.

\section{COMPARACIÓN DE LOS TEXTOS}

Si La danza de la Conquista es una adaptación de la de Moros y cristianos, puede suponerse que, primitivamente, sería una combinación de los atributos de ésta con las facultades y tradiciones de los indígenas en materia de danza, que sin duda los frailes no dejaron de aprovechar. Así pues debió nacer como una mezcla de diálogo, pantomima teatral, danza y su correspondiente música instrumental.

${ }^{32}$ De "zarzuela" la califica Arosamena (op. cit., p. 35). 
En su recorrido temporal y espacial, la danza perdió o ganó varios atributos: se enriqueció con el canto: una estrofa en la versión completa de Atempan, una tirada en la de Jalisco I, dos canciones breves en Jalisco II, dos canciones con varias estrofas en la versión de Sayula y varios dúos, solos y coros en la de Panamá. Otras veces, en cambio, el baile se redujo al mínimo (versión panameña) y otras, la "relación" se perdió (Aztecas y españoles) o se deformó por el uso y quizás por el mal conocimiento del castellano. Esta última característica de algunos grupos indígenas hizo que, algunas veces, los textos se tradujeran a la lengua de la región (por ejemplo, versión de Xico).

La música, acompañamiento del canto, de la danza y de la pantomima, se ajustó a las necesidades de las variantes o a la habilidad o conocimiento de sus ejecutantes, pero se mantuvo, al parecer, en todos los casos; los nombres de los sones sólo nos son conocidos en las versiones de Atempan, Xico y Sayula y en la versión de Aztecas y españoles y, en cuanto a la transcripción de la música, sólo aparece en tres publicaciones: la de Téllez Girón (versión de Atempan y Aztecas y españoles) y la de J. Arosamena (tres fragmentos, op. cit., p. 37-38). Los instrumentos varían según las regiones: jaranas en Veracruz, violín en Puebla, violín y tambor en Jalisco, violín, guitarra, tambor y triángulo en Panamá.

La versificación tiene también una gran variedad, producto de la intervención de distintos autores y recreadores: doble octosílabo pareado en la versión de Atempan, redondillas y pareados octosilábicos en la versión de Jalisco I, redondillas, pareados octosilábicos, décimas, sextillas y varias estrofas en verso de arte mayor en la versión Jalisco II, y toda clase de metros y estrofas de arte menor en las versiones de Sayula y Panamá, predominando en esta última la cuarteta hexasílaba con rima en los versos pares. Abunda notablemente la consonancia en el fragmento de Atempan y la asonancia en la versión panameña; las restantes versiones en castellano mezclan ambas formas de rima.

Los personajes son quizás más estables porque son los requeridos por la gesta: Moctezuma y sus caciques, Cortés y sus capitanes, y los soldados de ambos bandos. La Malinche (doña Marina) aparece en la mayoría de las versiones, excepto en las de Xico, Panamá y en Aztecas y españoles. Varían los personajes secundarios según la importancia del espectáculo: embajadores, mensajeros, graciosos, etc., así como los nombres de caciques y capitanes. Alvarado es personaje relevante en todas las versiones con "relación" y Cuauhtémoc aparece fugazmente en la versión de Sayula y, con un papel más amplio, en las de Xico y Jalisco II $^{33}$. El rey de Tlaxcala aparece en la versión de Sayula y en las de Jalisco, pero en la primera como simpatizante de los españoles y en las otras como todo lo contrario.

La estructura narrativa tiene una forma básica, que refleja los acontecimientos históricos: llegada de los españoles, enfrentamientos verbales y bélicos, victoria española y conversión india; sin embargo, hay diferencias notables en cuanto a su plasmación: embajadas, arengas, consultas, alabanzas, ofrecimientos y hasta más de una batalla. También existen episo-

${ }^{33}$ Debe ser un personaje incorporado tardíamente, ya que es el representante oficial de la resistencia indígena, cuyo "culto" se ha extendido por todo el país a raíz de las campañas "indigenistas" del gobierno revolucionario. 
dios particulares a una versión como el sueño y las ılucinaciones de Moctezuma en la de Sayula, el intento de envío a España del emperador y su posterior liberación en la versión panameña, la muerte próxima del emperador en Jalisco II y la segunda batalla que termina con el triunfo indígena en Aztecas y españoles. Los dos polos históricos: evangelización y conquista de la tierra rematan el eje de la trama; las diferentes versiones se acercan más a uno u otro: la evangelización parece estar ausente en Aztecas y españoles y es escasa en la versión de Panamá. Ambas dan preferencia a la faceta guerrera y su esencia es la lucha de conquista en la segunda y la resistencia efectiva en la primera. La versión Jalisco II es interesante porque en ella la resistencia toma un marcado tinte de patriotismo, de factura moderna, que se ha insertado abundantemente en los parlamentos indígenas; ello da un mayor realce a la parte guerrera, y la evangelización, que está presente, aparece disminuida frente a la importancia de la gesta azteca. En Jalisco I, en cambio, casi no se menciona el interés político y se da gran realce al tema religioso; la de Sayula atiende a ambas facetas y lo mismo parece suceder con la de Xico. El fragmento de Atempan se inscribe en el polo "conquista", pero no podemos asegurar que la versión completa siga esta línea.

Ya hemos visto detenidamente en el fragmento de Atempan el reflejo de los acontecimientos históricos en la trama de las "relaciones". En las restantes versiones encontramos más datos basados en la realidad, como la actitud de los tlaxcaltecas en favor de los españoles, que se simboliza en el sentir del rey de Tlaxcala de la versión de Sayula. La prisión de Moctezuma se halla en esta misma versión, así como en la panameña. La quema de las naves de Cortés se menciona en estas dos versiones que se acaban de citar. Asimismo, el emperador Carlos $V$ es insistentemente nombrado en la versión panameña y, parcamente en las de Jalisco, Xico y Sayula ("rey de España" en esta última). Los varios envíos de oro y plata que hizo Moctezuma a Cortés se mencionan en Jalisco I y en la versión panameña, y funcionan en las obras como sobornos, lo que va también de acuerdo con la realidad; sin embargo, no son aceptados por necesidades de las respectivas tramas (ni los portadores de la fe ni los aguerridos conquistadores pueden ser comprados). El amor entre Cortés y doña Marina aparece enunciado en la versión de Sayula y declarado en las de Jalisco.

Frente a estas diversas menciones de hechos históricos relevantes, que entran de manera natural en la trama, tenemos la avasalladora abundancia de referencias históricas de la versión Jalisco II, donde el recreador ha vertido toda la información que poseía citando nombres, localidades, describiendo en detalle acontecimientos fuera de la acción, introduciendo personajes irrelevantes, etc. Esta profusión rigidiza la obra y choca con la simplicidad de la trama de las demás versiones ${ }^{34}$.

Son interesantes las interpolaciones anacrónicas que remiten a otros acontecimientos de la vida del país; muestran, generalmente, la intervención popular que, simplista pero realísticamente, confunde los enemigos de ayer con los de hoy.

${ }^{34}$ Recuerda mucho los romances eruditos sobre temas históricos que había tratado laxamente el Romancero tradicional. La puntillosidad y platitud del cronista agosta los valores poéticos que pueda tener un texto. 
Es de lamentar el mal estado de algunos textos, que si bien no tienen un gran valor poético, relatan una tradición hístórico-legendaria digna de conservarse. El verso se convierte en prosa, las palabras se deforman y con ellas el sentido del relato. La pérdida de la claridad de los textos acabará por incidir sobre la vida de la danza, ya precaria como la de una buena parte de las manifestaciones folklóricas. Es éste, desde luego, un fenómeno inevitable y que tiene mucho que ver con el hecho de que los textos estén escritos en un lenguaje muy alejado del popular, con palabras altisonantes, pero incomprensibles aun para aquellos que tienen una mediana escolaridad. Además, aunque los ejecutantes hablen castellano, muchas veces no es ésta su lengua materna, lo que, además de contribuir a la falta de comprensión cabal de lo que recitan, no les incita a hacer ajustes o a variar lo dado.

Ya hemos dicho antes que los textos se mueven entre los polos de evangelización-conquista. Esto plantea graves problemas para el recreador mexicano, católico, pero que se siente parte del mundo indígena, no tanto por su sangre, ya que la mayoría de los recreadores no son indios, sino por su conciencia histórica de los tres siglos de dominación española, reforzada por la educación nacionalista que se da a los pueblos independientes con miras a su autoafirmación. Para el mexicano, el español es el conquistador, el enemigo, el que lo sojuzgó y del que se tuvo que liberar por las armas. La "relación" cuenta el inicio de esta conquista y el sometimiento de su pueblo; sin embargo, este sometimiento se hizo en nombre de la fe y la luz del evangelio fue traída por el opresor. El recreador se encuentra ante posiciones irreconciliables: su pueblo, su gente, buenos por ser los suyos, pero idólatras, que necesitaron ser conquistados por el español para conocer la religión verdadera. Hay que estar consciente de lo difícil de la posición del recreador mexicano ante la trama que enfrenta dos mundos, pero no externos a él, sino internos: su indigenismo y su catolicidad; ni uno ni otro pueden ser vencidos. Ante tal disyuntiva, los textos recreados reflejan siempre la tensión existente entre la religiosidad y nacionalismo.

Dos de las versiones citadas han podido resolver la contradicción: Aztecas y españoles ha eliminado la "relación" que la ataba al binomio conquista-evangelización, y ha combinado historia (invasión, lucha, victoria española) y ficción reivindicativa (nueva lucha, victoria indígena). Por su lado, la versión panameña, justamente por haber arraigado en otras tierras, no ha sentido la traba del nacionalismo. Cortés y sus hombres pueden permitirse el ser tan valientes y simpáticos como Moctezuma y los suyos, y Cortés mismo, ser magnánimo y liberar a los vencidos. Julio Arosamena nota esta ausencia de rencores que da ligereza al texto y lo despoja de toda tensión ${ }^{35}$.

Para resumir lo dicho: La danza de la Conquista, creada en la época colonial, sigue vigente en el México de hoy, pese a los varios factores en su contra: tema conflictivo para los recreadores, dificultades para su cabal comprensión de parte de los transmisores y trabas lingüísticas para una variación popular cómoda. Sin embargo, $L$ a danza... presenta un sinnúmero de variantes, producto de su inicial difusión espacial y de su larga vida. Es notable la gran libertad que existe en cuanto a su realización e

35 “.... a través de toda la 'acción guerrera' no existe una mayor agresión de combate... y llega al perdón" (op. cit., p. 35). 
interpretación dentro del marco argumental y es también de relevar la presencia, dentro de este marco, de datos reales, algunos quizás ya en la obra del primer autor. Amplia es también la gama de variantes que se presenta en música, acompañamiento y forma poética. En cuanto al fragmento que he tratado de reconstruir puede decirse que sigue la pauta general, pero resulta ser muy conservador en cuanto a forma poética y tratamiento del tema.

El Colegio de México.

Mercedes díAZ Roig

\section{ACERCA DE LA “ESTRATEGIA DE LA FICCIÓN” DE ROBERTO ARLT}

La obra de Roberto Arlt (1900-1942), sobre todo la narrativa, empieza a ser difundida fuera de Argentina hace aproximadamente diez años: se publican antologías en Cuba y México, la editorial Bruguera edita en España algunas de sus novelas y un volumen de cuentos, aparecen también las traducciones italiana y francesa de Los siete locos (1929) prologadas respectivamente por Juan Carlos Onetti y Julio Cortazár1. Pero este reconocimiento llega, no hay que olvidarlo, unos treinta años después de la muerte del escritor.

Convencido de la originalidad y autenticidad de su literatura, Arlt se queja en más de una ocasión, y en particular en el famoso prólogo a Los lanzallamas (1931), de la escasa sensibilidad crítica de sus contemporáneos, del menosprecio incluso ("el realista de pésimo gusto") con el que son recibidas y juzgadas sus narraciones. El nombre de Arlt aparece muy pronto asociado al grupo de Boedo (al cual nunca perteneció formalmente, pese a tener en él varios amigos), grupo que aglutina a escritores autodidactas, dedicados por lo general a la pintura realista y naturalista de los bajos fondos de Buenos Aires². Es sin embargo Ricardo Güiraldes -escritor cercano a los vanguardistas de Florida- que intuye el talento de Arlt y lo

\footnotetext{
${ }^{2}$ En 1967 David Viñas prepara para Casa de las Américas la primera antología sobre el escritor rioplatense; otra aparece en 1980 en siglo XXI, prologada por Noé Jitrik. También en 1980 Bruguera publica Los siete locos y la continuación de esta novela, Los lanzallamas, y en 1981 el libro de cuentos El jorobadito cuya primera edición es de 1933. La versión italiana de Los siete locos (Bompiani, Milán) es de 1971 y la francesa (Belfond, París), de 1981. A esta lista de publicaciones, hay que añadir la excelente edición en un solo tomo de Los siete locos y Los lanzallamas (1978) hecha por Biblioteca Ayacucho (Venezuela). Los datos anteriores hablan por sí solos del interés creciente que despierta Arlt en los últimos años, interés que reflejan también las cada vez más numerosas aproximaciones críticas a su obra.

2 Aunque aquí no viene al caso la discusión acerca de la "ubicación" de Arlt en Boedo o en Florida, importa saber que todavía hoy día no hay un consenso en torno a los vínculos del autor con dichos grupos. Adolfo Prieto señala que, debido a la "extrañeza" de su obra, "Arlt ha sido alternativamente reclamado como propio por memorialistas de Florida y Boedo [...] La amistad con Güiraldes, la publicación de dos relatos de Arlt en la revista Proa (1925) no prueban absolutamente la adhesión del novelista a las fórmulas literarias de Florida ni al tono vital de sus integrantes. Tampoco prueba demasiado en favor de Boedo el origen social del escritor, sus lecturas, el lenguaje empleado en los relatos, la aparente preocupación social de su novelística...", en Estudios de la literatura argentina, Buenos Aires, 1969, p. 52. Por nuestra
} 